\title{
Economic Applications of an Electronic Clinical Database for Nurse Practitioner Students
}

\author{
Michael J. Morgan, PhD, MPH, NP
}

PURPOSE. To describe the development of a Webbased clinical database that incorporates the standardized nursing languages (SNLs) used by nurse practitioner students, describe outcomes relative to the SNLs, and discuss economic aspects of outcome data.

METHODS. A mix of retrospective and prospective data of all outcomes for several cohorts (95 students, 17,193 records) comprised the data set.

FINDINGS. There is wide variation in use of SNLs as well as terminologies from other disciplines. The economic impact of patient encounters could be substantial.

CONCLusions. A Web-based clinical log provides an opportunity for NP students to collect and analyze data on clinical encounters.

Considerable resources must be invested in order to expand the use and sophistication of eClinicaLog.

Search terms: Advanced practice nursing, clinical log, eClinicaLog, NANDA, NIC, NOC, nurse practitioner education, nursing economics, nursing informatics
Applications économiques d'une base de données cliniques électroniques pour les infirmières en formation au rôle de praticienne avancée

But. Décrire le développement d'une base de données cliniques sur la toile, comprenant les langages normalisés (LN) utilisés par les infirmières inscrites à la formation de praticienne avancée, décrire les résultats en lien avec ces $L N$ et discuter des aspects économiques des résultats. MÉTHODES. Un ensemble de données rétrospectives et prospectives des résultats de plusieurs cohortes (95 étudiantes, 17,193 dossiers) fut étudié.

RÉSULTATS. Il y a de grandes disparités dans l'utilisation des $L N$ et de celle des autres disciplines. L'impact économique des consultations infirmières pourrait être substantiel.

conclusions. Une base de données cliniques électronique fournit la possibilité aux étudiantes avancées de collecter et analyser les données concernant leurs consultations. La pratique devient visible quand les $L N$ sont utilisés. Des ressources considérables devraient être investies afin d'augmenter l'utilisation et la sophistication d'un "eClinicaLog".

Mots-clés: eclinicaLog, NANDA, NIC, NOC, pratique avancée des soins

Translation by Cécile Boisvert, MSN, RN 


\section{Economic Applications of an Electronic Clinical Database for Nurse Practitioner Students}

Aplicações econômicas de uma base de dados clínicos eletrônica para alunos de prática avançada em enfermagem

objetivos. Descrever o desenvolvimento de uma base de dados clínicos baseada na Internet, que incorpore as linguagens padronizadas de enfermagem (LPEs) da NANDA, NIC e NOC utilizadas por alunos do curso de Prática Avançada em Enfermagem (PAE); descrever os resultados relativos às LPEs; e discutir aspectos econômicos dos dados referentes aos resultados. MÉTODo. O conjunto de dados compreendeu um "mix" de dados retrospectivos e prospectivos referentes a todos os resultados de vários coortes (95 estudantes e 17.193 registros).

ACHADOs. Há uma ampla variação no uso das LPEs, bem com de terminologias de outras disciplinas. O impacto econômico das consultas dos pacientes pode ser substancial. CONCLUSÕES. Um registro (log) clínico baseado na Internet oferece aos alunos de PAE uma oportunidade de coletar e analisar dados referentes a consultas de pacientes. A prática de enfermagem torna-se visivel quando as LPEs são utilizadas. Recursos consideráveis devem ser investidos a fim de expandir o uso e o aperfeiçoamento de um registro clínico eletrônico (eClinicalLog).

Palavras para busca: Prática Avançada em Enfermagem, registro clínico, registro clínico eletrônico, eClinical Log, NANDA, NIC, NOC.

Translation by Jeanne Michel, PhD, RN, and Alba de Barros, PhD, RN
Michael J. Morgan, PhD, MPH, NP, is Research Fellow, University of Michigan, Ann Arbor, MI.

$\mathbf{N}$ ble (Diers, 1992). Costs for nursing services have generally been part of the facility fee along with bricks and mortar. The salary and benefit line of a department of nursing's budget made it very easy to quantify the costs. The benefits of nursing services, however, have been more difficult to quantify. So much of nursing is targeted toward early detection, prevention, and monitoring-outcomes whose benefits or cost savings are nebulous. Indeed, it can be particularly dispiriting to have a grateful patient send a glowing letter praising other members of the healthcare team, yet give scant notice of the (often critical) nursing input. How many healthcare buildings are named for nurses? In a classic article that appeared in the New England Journal of Medicine (and other venues), Fagin and Diers (1983) explored a more philosophical reason why people do not give nurses credit publicly - the intimate nature of our work. We hesitate to compromise the intimacy. Therefore, nursing, as a discipline has had a hand in perpetuating its own invisibility.

Adding to the hazy economic analysis of nursing practice and outcomes is the lack of agreement on what is inside the black box of the profession. What is our contribution? What outcomes can be expected? Just what does the nurse do? Until fairly recently, there has not been language for nurses to use to describe their phenomena of interest, the goals they expect the patients to achieve, and the means by which the nurses will assist their patients to achieve those goals.

The discipline has not yet agreed on what our phenomena of interest are. Orem (2001) posits that nursing's "proper object" is "the inability of persons to provide continuously for themselves the amount and quality of required self-care because of situations of personal health" (p. 20). The phenomena of interest from the perspective of the other grand theories can be added to the growing list of "what nursing is all about." 
A broader, theoretical listing of phenomena of interest can be surmised in NANDA's (1996) Nursing Diagnoses: Definitions and Classification, 1997-1998. In Taxonomy I, diagnoses were grouped by nine human response patterns: Choosing, Communicating, Exchanging, Feeling, Knowing, Moving, Perceiving, Relating, and Valuing. This taxonomy continued through the 1990-2000 edition (NANDA, 1999). However, continued development has led NANDA to adopt a new organizing structure for subsequent editions, namely, Taxonomy II (NANDA, 2001).

In Taxonomy II, NANDA has reformulated its major organizing structure to employ a slightly modified version of Gordon's (1998) functional health patterns framework. It lists 13 domains: Health Promotion, Nutrition, Elimination, Activity/Rest, Perception/Cognition, SelfPerception, Role Relationships, Sexuality, Coping/Stress tolerance, Life Principles, Safety / Protection, Comfort, and Growth/Development (NANDA, 2001).

Given that there are phenomena of interest for the discipline, it would follow that there would be some outcomes in mind when those phenomena are addressed. The Iowa Outcomes Project (Johnson, Mass, \& Moorhead, 2000) has produced a listing of nursing outcomes (NOC). Each outcome has a varying range of indicators that can be rated for ongoing evaluation of what level of outcome the patient has achieved. In this taxonomy, outcomes are also grouped into domains, which are further divided into classes.

In order to achieve the outcomes, there are certain duties nurses perform or cause to be performed on the patient's behalf. The Iowa Intervention Project (McCloskey \& Bulechek, 2000) has produced four editions of the Nursing Interventions Classification (NIC), which contains listings of interventions also arrayed by domains and classes, although the domains are different from either NANDA II or NOC.

The contributions of the discipline, if codified, can become visible. Use of standardized nursing languages (SNLs) is growing, but slowly. Part of the delay is caused by the plethora of languages (the American Nurses Association recognizes about a dozen languages). However, if students of nursing become SNT-savvy, they will be better equipped to quantify the contributions of the discipline. Electronic data collection could provide the students and the discipline with standardized data that can be analyzed quickly and powerfully. The purpose of this article is to describe the development and implementation of an electronic database using one set of SNL (NANDA nursing diagnoses, NIC, and NOC) in primary care settings by nurse practitioner (NP) students and discuss economic applications of that use. The students enter their own data into an electronic database for their retrieval.

\section{Development of the Database}

The eClinicaLog ${ }^{\circledR}$ database is in its fifth major version. It was conceived initially as a method to track the number of patients NP students were seeing in their clinical practica. Other, somewhat similar efforts are found throughout NP educational programs. Criteria foundational for the development of this particular database included issues of retrievability, familiarity, availability, student buy-in, contribution to the discipline, and curricular congruence. In later versions, Health Insurance Portability and Accountability Act (HIPAA) compliance and economic sustainability figured prominently.

\section{Parameters}

Retrievability. The cumbersome nature of paperbased data collection became readily apparent. As use of the first version of the log readily demonstrated, more information (data fields) should have been added to gain a more detailed picture of what the patients were like and what the students were doing. Although it was easy to add up the number of patients seen in a week or semester, further analysis was tedious and time-consuming. Students were already well prepared regarding basic analysis and counting frequencies. Doing this manually did not use the students time efficiently, much less add to their skill set. An electronic format had to figure prominently into the next version. 


\section{Economic Applications of an Electronic Clinical Database for Nurse Practitioner Students}

Familiarity. The decision to base log development on commonly available software led to the adoption of Microsoft Access. The Microsoft Office suite, which contains MS Access, is included in many of the computer packages available when people purchase a computer. There are numerous Web sites for assistance, and support is readily available. In addition, commonly used languages - e.g., the International Classification of Diseases, 9th edition (ICD-9) (World Health Organization, 1992) — were to be used.

Availability. Initially, students were given disks with the log database already loaded. They used their own or campus computers with MS Access installed to enter their data. Periodically, they brought their disks to class and the instructor uploaded all the data to a central repository, a feature incorporated in Version 3. There were problems with availability, however, as students purchased or used varying versions of Access or other database software. Therefore, Version 4 launched a Webaccess feature. The log was then available at all times as long as the student had Internet access. Scheduled maintenance based on usage trends maximized availability.

Student buy-in. Students in graduate nursing programs tend to have multiple responsibilities. Their time is often tightly scheduled. They evaluate quickly the amount of time a pursuit will take vs. the payoff for that pursuit. Although students did spend a fair amount of time initially learning how to collect and input data, they quickly learned the next step - how to analyze their data. Over time, the Web-based version offered instant report generation. Once students saw examples of graphs and heard testimony of graduates regarding the use of data for career portfolios, buy-in became less of an uncertainty.

Contribution to the discipline. The decision in Version 3 of the clinical log to incorporate the NANDA and NIC codes was based on a projection of possible contribution to the discipline. Although there are other SNLs being used by other clinical logs, the logical progression and compatible formats among these systems drove the decision. NOC was added in version 4.0 of the log. Further refinements in version 4.5 included nesting the SNLs so that the diagnosis, outcome, and interventions were linked. Although this linkage might appear to be readily apparent, it was not part of the original log design. It is hoped that with a large data set, patterns will emerge regarding the types and frequencies of diagnoses, outcomes, and interventions selected. In addition, refinement of outcomes - especially the types of indicators chosen - may be possible. In this way, a pedagogic exercise would contribute to the advancement of the discipline.

Curricular congruence. Although possibly a subset of "student buy-in" and "contribution to the discipline," the idea of curricular congruence seemed to be another important parameter. Students typically progress from less acute, wellness-oriented assessment and intervention to more complex, illness/loss of function-oriented assessments and interventions. Although ICD-9 codes and the Evaluation and Management (E/M) codes may capture this for the medical aspects of patient encounters, the student's nursing repertoire also is supposed to be expanding. This developmental process should be reflected in increased sophistication in choice of nursing diagnoses, nursing-sensitive outcomes, and nursing interventions.

In addition, national standards for NP education (American Association of Colleges of Nursing, 1995; National Organization of Nurse Practitioner Faculties, 2003) contain broad curricular goals as well as specific competencies expected for NP students. Analysis of student data from the eClinicaLog or similar products could assist program directors to evaluate curriculum goals and outcomes. In the fourth version of the log, instructors were given the opportunity to instantly download all their students' data for analysis and, if necessary, intervention.

Given the broad scope of NP practice, it was decided to incorporate the languages of other disciplines. The ICD-9 was an obvious inclusion, as is the Common Procedural Terminology (CPT-3) (American Medical Association, 2003) and its E/M sets. In addition, medications were classified using the American Society of HealthSystem Pharmacists (AHFS, 2003) drug information codes. It is hoped that interdisciplinary interest will be facilitated by using these codes. 
HIPAA compliance. Detailed discussion of the ramifications of HIPAA are beyond the scope of this article. The Web-based version of this log was developed as implementation of HIPAA loomed on the horizon. Therefore, it was decided to include no individually identifiable health-related information. At no time were names, medical record numbers, Social Security numbers, addresses, or telephone numbers recorded. The negative impact of this decision was that data for an individual cannot be tracked over time, because each encounter is identified with a unique number. This is a small trade off when weighed against the need for confidentiality and integrity of information.

Economic sustainability. Given the academic base of this project, in-kind support has been the mainstay of its development. The initial, paper-based version had to be entered manually. As fortune would have it, the author had access to otherwise underutilized research assistants, who entered the data. This would prove to be prohibitively costly had it continued beyond the initial collection cycle. Use of MS Access for data entry greatly shaved costs but now limits the size of the active database. The number of fields (now 77) and the architecture of the database will require migration to Oracle or similar environment. Estimates for a 1-year license for a server running Oracle are in the $\$ 6,000$ range.

An unused server provided the basis for the initial Web-based version of the log. A similar hardware package would have cost about $\$ 8,000$. When faculty startup funds (amounting to $\$ 9,000$ ) at a new academic setting became available, they were used to pay for student assistants from the Information Technology graduate program. After the funds were expended, subsequent development funds became the responsibility of the author (current tally approximately $\$ 4,500$ ). Issues regarding supportability will be more fully discussed in the closing paragraphs of this article.

Timeline. The clinical database presented here has undergone three major phases. Each phase occurred because of opportunities, insights, and exigencies.

Version 1.0. This initial version featured some patient demographic fields (age, race/ethnicity, source of pay- ment) and fields that described the amount of supervision or independence the student had during that patient encounter. The ICD-9, CPT-3, and E/M were used to describe some medical aspects of the visit. The log also included investigator-generated codes for medication categories.

Version 1.0 was paper based. Papers were turned in to a research center, and as many fields as possible entered into MS Access by graduate research assistants. Codes from the AHFS Drug Information (AHFS, 2003) were assigned (for this version only) instead of the investigatorgenerated codes. This effort took four part-time graduate assistants two semesters and one summer to complete. Approximately one full-time employee (FTE) was needed for entering data. It was decided this version needed a major upgrade to meet the parameters mentioned above.

Version 3.0 APN Log. Given the major differences between the first version and the next set of improvements, the second phase of development was termed Version 3 and given the name "APN LOG." It featured MS Access as the database software, and students received disks with the database already copied on them. Version 3.0 incorporated four more languages: two from nursing, one from medicine, and one from pharmacy. In addition, a linked database containing information regarding the preceptors and practice sites was added.

The two nursing languages, NANDA diagnoses and NIC, were unlinked - i.e., students listed up to three nursing diagnoses and up to three nursing interventions. Hard copy lists and texts provided guidance. Use of the NANDA Taxonomy I codes (e.g., risk for infection in Taxonomy I was 1.2.1.1) were problematic as a result of numerous data entry errors.

For the first time, the AHFS was incorporated into the data-collection form. Initially, the broad categories were used (the first two digits). However, students began adding specificity (and digits) on their own.

Greater detail regarding student performance was possible using CPT-3. Students were furnished a preliminary list of "likely procedures" gleaned from encounter sheets from area primary care practices. Students sent 


\section{Economic Applications of an Electronic Clinical Database for Nurse Practitioner Students}

email to the investigator to request codes for procedures not on this list if they were not able to find the codes on their own.

Students entered their data onto disks and gave copies of their disks to the research assistants who uploaded them to a central repository. In addition, the student assistants transcribed the paper copies of version 1 into this new format. This effort took four part-time student assistants two semesters and one summer to complete. One FTE was needed for this work.

Version 4.0. The innovative feature of this version was conversion to fully Web-based data entry. As long as students (or instructors) had access to the Internet, they could enter and download data. This development made possible by having server capacity, maintenance, and support supplied by the academic institution. Standardized nursing language was further incorporated by adding NOC codes. NANDA's Taxonomy II codes (now 5 digits and no periods - the code for risk for infection in Taxonomy II is now 00004) were added, which greatly improved input accuracy.

Students log into the Web site using their unique identifier and passwords. Students may change their passwords at any time, and their passwords are archived in a file that can be accessed by the instructor in case the students forget their passwords (a common occurrence). Once logged into the Web site, students can choose to review data, revise it, enter new data, or download it. Students have access only to their own data. Should students wish to enter data, a Web form is displayed (Figure 1). Data are collected and stored via ASP in an Access database.

Version 4.5, eClinicaLog. The latest version, 4.5, includes two major upgrades, apart from the name change. The first upgrade allowed students to immediately generate reports from several of the major variables in their data base. By clicking on a button, students can download a data table and import that into MS Excel or SPSS. Students can manipulate their data and generate professional-looking graphics.

The second major upgrade linked NANDA diagnoses, NOC, and NIC. For the first time, students were able to identify a single diagnosis, link it with an outcome (and specify up to four indicators for that outcome), and list up to three interventions aimed at achieving that outcome. Students could do this for up to three nursing diagnoses.

A third, minor change improved speed in data entry. The first block of data (program data) would pop up automatically after being entered the first time of each session. For example, the students enter the date of service, the course name, and the preceptor code once each session. For subsequent encounters, that information is then filled in the form automatically.

\section{Summary}

At this time, there are 77 fields in use. Variables are grouped into program data (course, preceptor, clinical site), patient data (age group, gender, race/ethnicity, and payer source), interdisciplinary data (ICD-9, AHFS, CPT-3, student involvement, time spent), and SNL data (NANDA, NOC, NIC). Instructors and visitors have around-the-clock access to the Web site. Patient data are not traceable to individuals. For a full description, see information posted at http://eClinicaLog.org, and enter as VISITOR.

\section{Methods}

This analysis was reviewed by a university Human Investigations Committee and determined to be exempt from full review. The aims of the analysis were to report on the outcomes of one method for describing the clinical experience of NP students and to describe practice characteristics of students in two advanced practice nursing programs. Data were aggregated from several cohorts of students who attended two different universities, both in the upper Midwest. Cohorts 1 and 2 comprised family NP students $(n=66)$ who collected data during three of their four clinical practica. Cohorts 3 to 5 comprised adult NP students $(n=29)$ who collected data during all four of their clinical practica. It should be noted that most NP programs have three or fewer semesters of clinical practica. Table 1 contains information regarding the cohorts. 
Figure 1. Current Interface Appearance

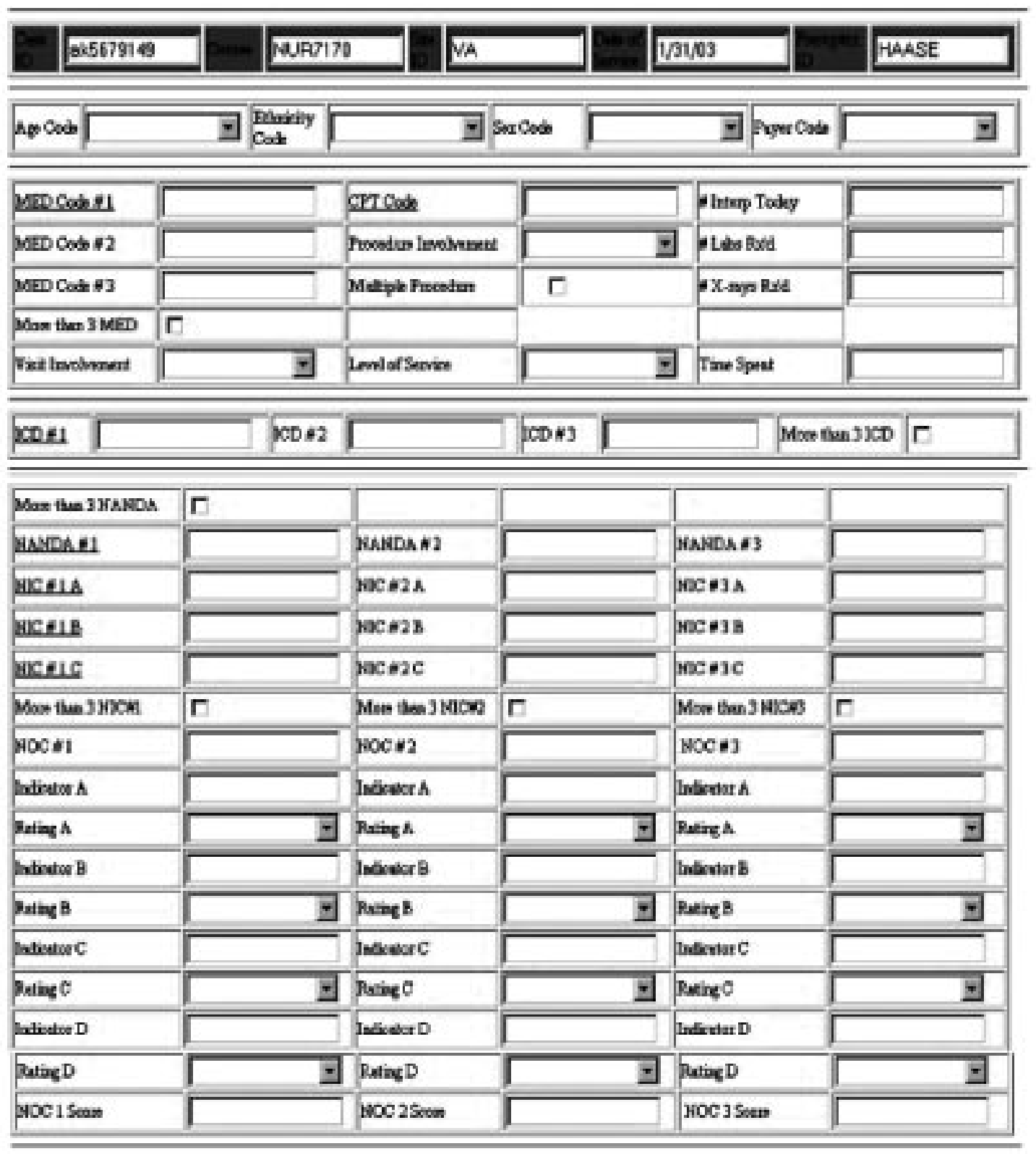




\section{Economic Applications of an Electronic Clinical Database for Nurse Practitioner Students}

Table 1. Cohort Description

$\begin{array}{ccccc}\text { Version } & \text { Cohort } & \text { University } & \text { Program } & \begin{array}{c}\text { Number of } \\ \text { Semesters }\end{array} \\ 1.0 & 1 & \text { A } & \text { Family NP } & 3 \\ 3.0 & 2 & \text { A } & \text { Family NP } & 3 \\ & 3 & \text { B } & \text { Adult NP } & 4 \\ 4.0+ & 4 & \text { B } & \text { Adult NP } & 4 \\ & 5 & \text { B } & \text { Adult NP } & 4\end{array}$

Table 2. Most Frequent Nursing Diagnoses, by Version of Clinical Log

\begin{tabular}{|c|c|c|c|}
\hline \multicolumn{2}{|c|}{ Version 3.0} & \multicolumn{2}{|c|}{ Version $4.0+$} \\
\hline 00084 & $\begin{array}{l}\text { Health seeking } \\
\text { behavior }\end{array}$ & 00126 & Deficient knowledge \\
\hline 00126 & Deficient knowledge & 00132 & Acute pain \\
\hline 00132 & Acute pain & 00084 & $\begin{array}{l}\text { Health seeking } \\
\text { behavior }\end{array}$ \\
\hline 00133 & Chronic pain & 00133 & Chronic pain \\
\hline 00099 & $\begin{array}{l}\text { Ineffective health } \\
\text { maintenance }\end{array}$ & 00082 & $\begin{array}{l}\text { Effective therapeutic } \\
\text { regimen management }\end{array}$ \\
\hline 00092 & Activity intolerance & 00076 & $\begin{array}{l}\text { Readiness for enhanced } \\
\text { community coping }\end{array}$ \\
\hline 00080 & $\begin{array}{l}\text { Ineffective family } \\
\text { therapeutic regimen } \\
\text { management }\end{array}$ & 00046 & Impaired skin integrity \\
\hline
\end{tabular}

\section{Procedures}

Data entry was achieved by three methods. For Cohort 1 , student researchers entered data from paper logs. For Cohort 2, data were entered by the students directly into Access 98 and uploaded by the instructor into a common database. Cohorts 3 to 5 entered their data via the Internet. Data were collected via a Web form and transferred to an Access 2000 database that resided on the same server. Data were then copied from the Access file and imported into Excel for initial analysis. At this point, empty cells were deleted and the most frequent responses were identified. Obvious data entry errors were corrected. The dataset was then imported into SPSS 11.0 for analysis. Frequency tables were again constructed.

\section{Results}

\section{Sample}

Version 1.0 contained 7,401 records (each encounter generates a record). Version 3.0 contained 6,007 records. Versions 4.0 and 4.5 (hereinafter referred to as $\mathrm{v} 4.0+$ ) contained 3,785 records. Therefore, analysis is based on data from 16,833 encounters entered into the final database.

\section{Nursing-Oriented Variables}

Data relating to the use of SNL were analyzed for frequency. Nursing diagnoses, nursing outcomes, and nursing interventions were arrayed by frequency. Results for NANDA and NIC codes will be reported here (there were too few NOC codes in the database to support analysis).

Nursing diagnoses were collected starting with v3.0. This was aided by NANDA's adoption of Taxonomy II (NANDA, 2001). The most frequently entered codes are summarized in the following three tables, by version. The listing is truncated where there was a precipitous drop-off in frequency of labels used. In Table 2, the NANDA codes are listed with the more frequently documented codes at the top.

Nursing interventions (McCloskey \& Bulechek, 2000) were tracked for all versions of the log. In v1-v3, students entered up to three NIC codes. In v4.0+ codes were linked to specific nursing diagnoses. Table 3 contains the five most frequently employed NIC codes entered into the "first nursing intervention" field for each version.

\section{Medically Oriented Variables}

There were several medically oriented variables included in the database throughout its development. 
Since advanced practice nursing students also must master the language of other disciplines, use of standardized languages across disciplines provided an opportunity for comparison. The ICD-9 was used to document medical diagnoses. Up to five digits can be used. Each digit connotes increased specificity. Students most often used the codes supplied by each preceptor site, but they also had the use of hard copy and Web-based support. Common diagnoses are summarized in Table 4.

The CPT is a system for coding medical procedures. While that system was used in the clinical log, it is not reported here because of the narrow range of procedures documented.

The AHFS was employed by students to document medications ordered. It uses a three-part taxonomy with each section demarcated by punctuation. The major classification comprises the first two digits followed by a colon. The next two classification strata are of two digits each and are separated by a period. Specific analysis of that variable will be found in subsequent manuscripts.

\section{Economic-Oriented Variables}

Although the federal government does not reimburse through the Medicare program for student services (in any discipline), the base reimbursement rate can be used for a standardized measure of the reimbursement that could have been realized. The Centers for Medicare and Medicaid Services (CMS, 2003) publishes reimbursement schedules for credentialed providers who agree to Medicare's terms of participation. These schedules take into account regional economic differences as well as clinical intensity measures associated with delivering services. Of the two states included in these cohorts, the lower geographic index was used as conservative estimates, and totals are included only for relative comparison only (Table 5).

\section{Discussion and Implications}

\section{Limitations}

Except for the first 3,000 or so records (which were entered by research assistants who performed data quality checks), students entered data directly. There was no verification of the appropriateness or accuracy of the selection of codes for various languages save for obvious typing errors. As students became more familiar with the languages, especially with the ICD and differential medical diagnosis, they may have developed greater sophistication and discernment. As noted in other studies (Crabtree, Hameister, Pohl, Warren, \& Allan, 1999), the number of diagnoses were limited to three. In v4.0+ students could enter up to three NIC codes per nursing diagnosis. Comparison across studies is limited by the paucity of information provided regarding actual SNL and other language codes in published reports.

\section{Minimum Data Sets and Standardized Nursing Language}

The Nursing Minimum Data Set (Werley \& Lang, 1988) provides the framework for collecting data system-

Table 3. Most Frequent Nursing Interventions, by Version of Clinical Log

\begin{tabular}{|c|c|c|c|c|c|}
\hline \multicolumn{2}{|c|}{ Version 1.0} & \multicolumn{2}{|c|}{ Version 3.0} & \multicolumn{2}{|c|}{ Version $4.0+$} \\
\hline 5510 & Health education & 5510 & Health education & 5602 & Teaching: Disease process \\
\hline 5606 & Teaching: Individual & 6520 & Health screening & 1400 & Pain management \\
\hline 6520 & Health screening & 4920 & Active listening & 2380 & Medication management \\
\hline 5616 & Teaching: Prescribed meds & 5602 & Teaching: Disease process & 5510 & Health education \\
\hline
\end{tabular}




\section{Economic Applications of an Electronic Clinical Database for Nurse Practitioner Students}

Table 4. Most Frequent Medical Diagnoses, by Version of Clinical Log

\begin{tabular}{|c|c|c|c|c|}
\hline Version 1.0 & \multicolumn{2}{|c|}{ Version 3.0} & \multicolumn{2}{|c|}{ Version $4.0+$} \\
\hline V70.0 Medical exam & 401.1 & Hypertension & 401 & Hypertension \\
\hline V20.2 Infant/child health check & 250 & Diabetes mellitus & 250 & Diabetes \\
\hline V72.3 GYN exam & 465.9 & Acute URI NOS & 272 & Disorders of lipid metabolism \\
\hline 465.9 Acute URI NOS & 493 & Asthma & 716 & Other arthropathies \\
\hline 401.1 Hypertension & 496 & COPD (NOS) & V70 & Medical exam \\
\hline 382.9 Otitis media NOS & 461.9 & Acute sinusitis NOS & V72.3 & GYN exam \\
\hline Acute bronchitis & & & & \\
\hline Asthma & & & & \\
\hline
\end{tabular}

Table 5. Potential Reimbursement in 2001 Dollars for the Most Frequent E/M Level of Service Codes (n), by Version of Clinical Log

\begin{tabular}{|c|c|c|c|c|}
\hline Codes & v1.0 & v3.0 & v4.0+ & Total \\
\hline $\begin{array}{l}99213 \text { (Established } \\
\text { patient, low) }\end{array}$ & 3,089 & 2,374 & 1,628 & 236,981 \\
\hline $\begin{array}{l}99214 \text { (Established } \\
\text { patient, moderate) }\end{array}$ & 1,131 & 1,329 & 665 & 171,094 \\
\hline $\begin{array}{l}99212 \text { (Established } \\
\text { patient, minimal) }\end{array}$ & 2,331 & 680 & 238 & 59,068 \\
\hline $\begin{array}{c}99204 \text { (New patient, } \\
\text { moderate) }\end{array}$ & & & 286 & 28,666 \\
\hline $\begin{array}{c}99203 \text { (New patient, } \\
\text { moderate) }\end{array}$ & & & 233 & $\begin{array}{r}15,811 \\
511,620\end{array}$ \\
\hline
\end{tabular}

Medicare fees from the 2001 schedule using the lower geographic index and facility fee.

atically regarding nursing and the clients served, especially the Nursing Care Items category. There are a few variables from this set that are missing in eClinicLog: baseline functional assessment, information regarding treatment location, and information more appropriate for an acute care setting, such as discharge date/disposition. As noted above, no protected health information was gathered. The purposes of this database do not include being a comprehensive data set.

Zielstorff (1988) framed the task of describing nursing phenomena when she focused on the issues of retrievability. Noting that since so much of what nurses do is textual in nature, she urged nurses to "store numeric data in its original form whenever possible, and to code text to the greatest degree necessary for retrieval" (p. 69). In that sense, the use of NANDA, NOC, and NIC provides a uniform manner of reducing complex nursing assessment, decisions, and actions into a readily retrievable format. In doing so, standardized nursing language provides the mechanism for reporting phenomena across settings.

\section{Application and Implications}

There have been just a handful of published articles describing the clinical experiences of NP students. Meisner, Sharp, and Fuller (1997) focused on the technology employed to collect data from NP students. Similarly, Jones and Clark (1999) described the use of a scannable $\log$ for pediatric NP students. Crabtree et al. (1999) reported on a comparison of clinical experiences of NP students from four programs from across the United States. It is this last study with which the eClinicaLog results 
can be compared only with respect to the "complexity" issues. Although the authors stated that complexity was "based on Medicare guidelines" and was referred to as "brief, limited, intermediate, and comprehensive," data were gathered, but not fully reported, regarding "new patients" vs. "return patients."

O'Connor, Hameister, and Kershaw (2000) reported on a database that focused on "core health data elements" and NANDA and NIC. Their aim was to describe the relationship between core data elements and standardized nursing language. Although students did not enter data electronically, they used data-collection sheets. This provided enough data to allow the investigators to discern diagnostic reasoning patterns that could be grouped into four categories: focused assessments, clinical diagnosis, standardized nursing language, and outcomes. Data collected from the eClinicaLog project would be subjected to secondary analysis and possibly incorporate the other languages that the $\mathrm{O}^{\prime}$ Connor study did not.

\section{Curricular Innovation}

The impetus behind the development of the eClinicaLog was to provide NP students the opportunity for hands-on experience regarding description and analysis of their practice. Although health care is a multidisciplinary pursuit and students should be exposed to and conversant with the language of several disciplines, it has been a common occurrence that graduate nursing students lack a solid foundation in standardized terminologies of their own discipline. Some even lack a passing familiarity with the contributions of their discipline to patient outcomes. Therefore, the eClinicaLog becomes a common thread throughout the clinical practica so that students continuously interact with their own data as they try to describe their phenomena of concern, their client-oriented outcomes, and the nursing interventions they employed. In addition, using taxonomies from a variety of disciplines provides students ample opportunity to compare the various approaches.

The culminating project for one NP program guides students to make a professional portfolio that includes description and analysis of all the data collected during their clinical experience. This type of project involves all the fundamental and critical thinking skills that the program intends to develop in its graduates.

\section{Future Directions}

There are many avenues that could be explored. Central to its purpose, this log should be validated by practicing NPs to compare actual practice patterns with those that educators hope to simulate in a clinical practicum. Is the case mix the same? Are NPs being educated for the practice that lies ahead? In addition, curricula can be assessed for comprehensiveness and effect by monitoring patterns in diagnosis, treatment, and outcomes. For example, does the topical outline cover the more common clinical issues in appropriate depth? Do students show evidence of increasing sophistication regarding their facility with their own discipline?

Another avenue could that of building the framework for a data warehouse. If enough NPs began collecting similar data using SNLs in such a way that they could be exported to a common database, a critical mass of information could be established so that certain questions finally can be explored. For instance, which nursing interventions, in what dose, for which populations would result in certain outcomes? Which indicators (from a long list of indicators) are most sensitive regarding a wide array of nursing outcomes? This type of work is being done in the acute care setting via the HANDS Project (Keenan et al., 2002).

Finally, clinical information systems could be modified to incorporate nursing oriented information. Instead of a stand-alone system like the eClinicaLog, nurses and others would input data as a matter of course. Intensity measures, currently limited to a proxy measure of the $\mathrm{E} / \mathrm{M}$ codes, could be developed that are more sensitive to nursing input.

No discussion of economic applications would be complete without addressing the issue of economic sustainability. At present, there is almost no commercial interest in designing and marketing a clinical log such as 


\section{Economic Applications of an Electronic Clinical Database for Nurse Practitioner Students}

eClinicaLog. The academic environment with its infrastructure has made this project possible. In addition, use of the various languages is permissible as there are no fees involved: eClinicLog is, in a sense, a research project. Were a fee to be charged for use of the log, agreements with the owners of several of the languages would have to be renegotiated.

Few deans (or researchers) could be expected to fund a clinical $\log$ indefinitely. It is quite likely that eClinicaLog will have to be made available on a fee basis, with a cost-recovery model as the most likely billing schedule. Server support and maintenance, license fees, and training make up the bulk of expenses attributable to the total cost of a log. These are expenses that are not readily covered by grants. Therefore, students and programs probably will need to supply the financial support if this project is to continue growing. Acceptance of a financial investment by the students and programs is a variable that remains to be quantified.

Acknowledgement. This work was partially supported by a Postdoctoral Fellowship, Grant \# 5-T32-NR0707312, Health Promotion/Risk Reduction Interventions Training, National Institute of Nursing Research, C. Loveland-Chery, P.I.

Author contact: mjmorgan@umich.edu, with a copy to the Editor: rose_mary@earthlink.net

\section{References}

American Association of Colleges of Nursing. (1995). Essentials of graduate nursing education. Washington, DC: Author.

American Medical Association. (2003). Common procedural terminology. Chicago: AMA Press.

American Society of Health-System Pharmacists. (2003). AHFS drug information. Washington, DC: Author.

Centers for Medicare and Medicaid Services. (2003). Physicians fee schedule. Accessed November 18, 2003, from www.cms.gov/physicians/ pfs/

Crabtree, K., Hameister, D., Pohl, J., Warren, B., \& Allan, J. (1999). Analysis of student nurse practitioner primary care practice patterns in the northwest, midwest, and south. American Journal for Nurse Practitioners, 3(5), 9-11, 13-14, 17-19, 23-24.
Diers, D. (1992). On things strange ... how nursing is treated, ignored, or otherwise not given credit. Image: The Journal of Nursing Scholarship, 85, 86.

Fagin, C.M., \& Diers, D. (1983). Nursing as metaphor. New England Journal of Medicine, 309, 416-417.

Gordon, M. (1998). Manual of nursing diagnosis, 1995-1996 (7th ed.) St. Louis: Mosby-Yearbook.

Johnson, M., Maas, M., \& Morehead, S. (Eds.) (2000). Nursing outcomes classification (NOC) (2nd ed.). St. Louis: Mosby.

Jones, M.E., \& Clark, D.W. (1999). Measuring nurse practitioner student clinical outcomes using a scannable log. Journal of the American Academy of Nurse Practitioners, 11, 200-205.

Keenan, G.M., Stocker, J.R., Geo-Thomas, A.T., Sorparkar, N.R., Barkauskas, V.H., \& Lee, J.L. (2002). The HANDS project: Studying and refining automated data collection of a cross-setting clinical data set. Computers, Informatics, Nursing 20, 89-100.

McCloskey, J.D., \& Bulechek G. (2000) (Eds.). Nursing interventions classification (NIC) (3rd ed.). St. Louis: Mosby.

Meisner, T.R., Sharp, H.F., \& Fuller, S.G. (1997). Development of a computerized nurse practitioner student experiential log using optical mark-sense technology. Clinical Excellence for Nurse Practitioners 1, 198-206.

National Organization of Nurse Practitioner Faculties. ( 2003). Curricular guidelines for nurse practitioner programs. Washington, DC: Author.

North American Nursing Diagnosis Association. (1996). NANDA nursing diagnoses: Definitions and classification, 1995-1996. Philadelphia: Author.

North American Nursing Diagnosis Association. (1999). NANDA nursing diagnoses: Definitions and classification, 1999-2000. Philadelphia: Author.

North American Nursing Diagnosis Association. (2001). NANDA nursing diagnoses: Definitions and classification, 2001-2002. Philadelphia: Author.

O'Connor, N.A., Hameister, A.D, \& Kershaw, T. (2000). Developing a database to describe the practice patterns of adult nurse practitioner students. Journal of Nursing Scholarship, 32, 57-63.

Orem, D.E. (2001). Nursing: Concepts of practice (6th ed.). St. Louis: Mosby.

Werley, H.H., \& Lang, N.M. (Eds.) (1988). Identification of the minimum nursing data set. New York: Springer.

World Health Organization. (1992). International statistical classification of diseases and related health problems (9th ed. rev.). Geneva: Author.

Zielstorff, R.D. (1988). Considerations in data capture, storage, and retrieval for the nursing minimum data set. In H.H. Werley \& N.M. Lang (Eds.), Identification of the minimum nursing data set (pp. 67-83). New York: Springer. 